\title{
Locomotory activity and exploration behaviour of juvenile European lobsters (Homarus gammarus) in the laboratory
}

\author{
FOLKE MEHRTENS $^{1}$, MAREIKE STOLPMANN ${ }^{2}$, \\ FRIEDRICH BUCHHOLZ ${ }^{1}$, WILHELM HAGEN ${ }^{2}$ \& \\ REINHARD SABOROWSKI ${ }^{1}$
}

${ }^{1}$ Biologische Anstalt Helgoland, Alfred Wegener Institute for Polar and Marine Research, 27483

Helgoland, Germany and ${ }^{2}$ University of Bremen, Marine Zoology,

P.O. Box 330440, 28334 Bremen, Germany

(Received 22 April 2004; in final form 24 fanuary 2005)

\begin{abstract}
The behaviour of juvenile European lobsters (Homarus gammarus) in the wild is little understood. A laboratory system was designed with a maze-like environment as an alternative to the large technological expenditure of a field study. It provided an apparently endless runway with uniform thigmotactical cues. Juvenile lobsters having a total length of 68 to $115 \mathrm{~mm}$ were studied. The lobsters showed an extensive nocturnal locomotory activity. They established home shelters in which they spent the day and covered distances of 1200 to $1600 \mathrm{~m}$ during the night. On average, the lobsters performed 136 excursions from their shelters, of which $10 \%$ led only to the immediate surroundings of the shelters. Of all the excursions $90 \%$ were shorter than $16 \mathrm{~m}$. In some exceptional cases distances of several hundred meters were covered in the maze between shelter visits. Excursions of less than $16 \mathrm{~m}$ lasted on average less than $5 \mathrm{~min}$. The frequencies of shelter visits during the dark phase were highest in small lobsters (300 visits) and lowest in larger lobsters (50 visits). The time spent within shelters decreased from $10 \%$ to less than $2 \%$ with lobster size. A distinct change in behaviour was obvious at a body length of 75 to $80 \mathrm{~mm}$. Smaller lobsters behaved defensively and relied on shelter protection. Larger lobsters were less dependent on shelter protection and thus were able to explore and utilize their environment more intensively.
\end{abstract}

Keywords: Homarus gammarus, behaviour, locomotory activity, maze, walking distance, diel rhythm 


\section{Introduction}

European lobsters (Homarus gammarus) are widely distributed along the west coasts of Europe, occurring from the North Cape to the Iberian Peninsula and further south off Morocco and around the Azores. They are also present in the Mediterranean Sea eastward to the Strait of Bosporus (Holthuis 1974; Williams 1988). Lobsters prefer rocky habitats which provide shelters. In the North Sea they are mainly restricted to the British and Norwegian coast. In the south-eastern North Sea, where the sea bed is predominantly soft, the only suitable lobster habitat exists around the rocky island of Helgoland (Ulrich et al. 2001).

On Helgoland, lobsters were a major part of the fisheries from the 19th century (Ehrenbaum 1894) to the 1930 s, when lobster catches amounted to $40,000 \mathrm{~kg}(\approx 80,000$ animals) p.a. (Goemann 1990). However, landings decreased drastically from the $1960 \mathrm{~s}$ reaching a minimum of about $50 \mathrm{~kg}(\approx 100$ animals $)$ p.a. in the $1990 \mathrm{~s}$. Currently, the lobster catches remain steady at this low level (Ulrich 1998). The reasons for the collapse of the stock may be a combination of fishing pressure (Harms et al. 1995), water pollution (Lozán et al. 1990) and interspecific competition between lobsters and the edible crab Cancer pagurus (Ulrich 1998).

Since the Helgoland lobster population is widely isolated from other populations (Ulrich et al. 2001) the stock is unlikely to recover through immigration of foreign individuals. Apart from fishing restrictions, a sustained restocking programme of adults can be complemented by the release of juveniles to the wild (van der Meeren \& Næss 1991). The survival of the released juveniles increases with their ability to assert themselves against predators and conspecifics. While the biology of adult lobsters has been thoroughly investigated, there is still a considerable lack of knowledge about the ecological requirements and the behaviour of juveniles (Linnane et al. 2001).

Accordingly, the objective of this work is to study in the laboratory the exploration behaviour and the locomotory activity of juvenile lobsters and to investigate the variation of behaviour in relation to the size of the animals. A further goal is to define the best trade-off between lobster size and behavioural activity, which would improve the survival of released laboratory-reared juveniles. Previous work has shown that lobsters orientate thigmotactically moving along the inner walls of their rearing tank (Ulrich, personal communication). Therefore, we developed a maze system, which provided similar tactile stimuli in an apparently endless runway. The lobsters were video-recorded and their locomotory performance, walking velocities, frequencies and durations of shelter visits were analysed.

\section{Material and methods}

\section{Origin of animals}

The investigations were carried out during spring 2002 at the Marine Station on Helgoland. Juvenile European lobsters (H. gammarus) were provided by the lobster-rearing facilities. Animals of different sizes, total lengths $68-115 \mathrm{~mm}$, were selected for the experiments. The total length, carapace length and mass of the lobsters are listed in Table I. The total length is the length measured from the tip of the rostrum to the end of the telson.

\section{Maintenance and experimental procedure}

Prior to the experiments, juvenile lobsters were adapted to the experimental conditions. First, they were kept individually at $9-10^{\circ} \mathrm{C}$ in aerated $10-\mathrm{L}$ basins for $24 \mathrm{~h}$ and were 
Table I. Individual (ID), age, total length (TL), carapace length (CL, $-\mathrm{R}=$ without rostrum, $+\mathrm{R}=$ with rostrum) and masses of juvenile lobsters used for the exploration experiments.

\begin{tabular}{lcccr}
\hline $\begin{array}{l}\text { Individual } \\
\text { (ID) }\end{array}$ & $\begin{array}{c}\text { Age } \\
(\text { months })\end{array}$ & $\begin{array}{c}\text { Total length (TL) } \\
(\mathrm{mm})\end{array}$ & $\begin{array}{c}\text { Carapace length (CL) } \\
(\mathrm{mm},-\mathrm{R},+\mathrm{R})\end{array}$ & $\begin{array}{c}\text { Mass } \\
(\mathrm{g})\end{array}$ \\
\hline $64 / 00$ & 23 & 68 & 27,32 & 7.7 \\
$259 / 00$ & 22 & 71 & 26,32 & 8.8 \\
$69 / 00$ & 23 & 72 & 27,34 & 9.7 \\
$141 / 00$ & 22 & 77 & 27,33 & 11.6 \\
$977 / 99$ & 32 & 81 & 33,38 & 13.8 \\
$963 / 99$ & 32 & 84 & 34,37 & 15.3 \\
$1237 / 99$ & 32 & 97 & 35,47 & 26.1 \\
$987 / 99$ & 32 & 107 & 36,46 & 30.6 \\
$1411 / 99$ & 31 & 115 & 41,52 & 38.5 \\
\hline
\end{tabular}

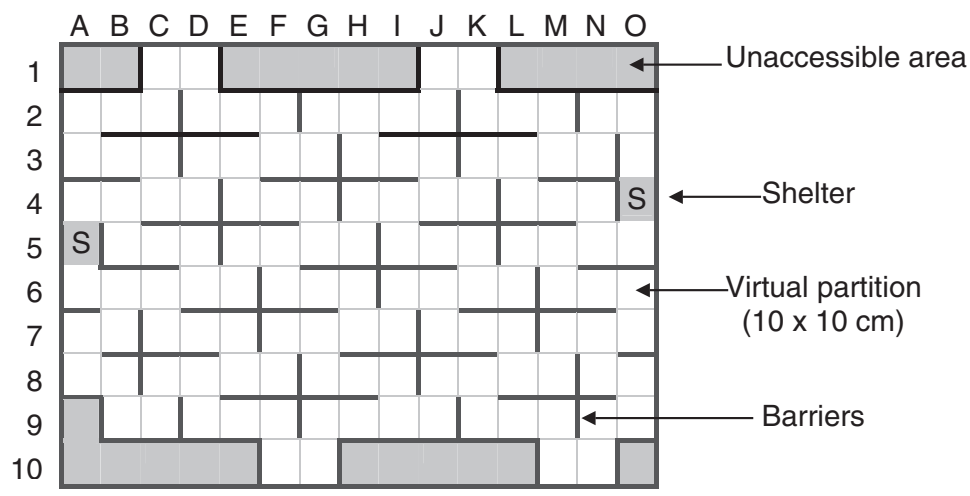

Figure 1. Design of the maze. The overall dimensions of the basin were $1 \times 1.5 \mathrm{~m}$. Bold black lines represent barriers. Grey lines illustrate the virtual partition of the maze into squares of $10 \times 10 \mathrm{~cm}$. The squares were defined by numbers and letters. The areas shaded grey show the inaccessible parts of the maze. The positions of the shelters are indicated by " $S$ ".

fed with frozen fish. Thereafter, the lobsters were transferred to the maze basin (Figure 1) and allowed to acclimate to the experimental conditions for another $24 \mathrm{~h}$. The area of the maze was $150 \times 95.5 \mathrm{~cm}$ and the water level was $12-15 \mathrm{~cm}$. The basin was subdivided by cross-shaped Perspex walls. These subdivisions were spaced at $10 \mathrm{~cm}$ and arranged to form a grid of squares of $10 \times 10 \mathrm{~cm}$. This arrangement provided a continuous walking track through this maze. Some squares close to the edge of the basin were separated from the maze to avoid dead-ends of the track. The maze was equipped with two tunnel-shaped shelters made of concrete $(3 \times 6 \times 12 \mathrm{~cm})$ which were placed at either side of the basin (Figure 1). Seawater at a constant temperature of $9-10^{\circ} \mathrm{C}$ was continuously supplied during the entire experimental period with a flow rate of $1.5 \mathrm{~L} \mathrm{~min}^{-1}$. The flow rate was high enough to ensure sufficient water exchange but was also low enough to avoid a distinct water current through the maze, which might have affected the behaviour of the lobsters. Two identical mazes were used. Alternately, one served as the acclimation basin while the other was used as the experimental basin. The room was illuminated with neon light of 300 to 350 lux. The light cycle was adjusted to $12 \mathrm{~h}: 12 \mathrm{~h}$ (light/dark). The dark phase started at 18:00 and ended at 06:00.

After the acclimation period an infrared camera (Simrad OE 1232, UK) and two infrared spotlights were placed above the experimental basin. Video recording started at 15:00 and 
ended at 09:00 the next day. Two VCRs were used successively during one experiment, each recording a 300-min tape (Sony E $300 \mathrm{VHS}$ ). In the long-play mode, both video tapes covered $18 \mathrm{~h}$ of the experiment. This included the complete dark phase $(12 \mathrm{~h})$ and $3 \mathrm{~h}$ of light before dark as well as $3 \mathrm{~h}$ of light after dark. Each of the nine lobsters was observed for one night.

\section{Evaluation of video tapes}

The walking distance and the walking speed were determined by counting the squares that the lobster had passed, taking a distance of $10 \mathrm{~cm}$ between squares as a basis. In order to reduce the amount of data, but to obtain a representative data set, we analysed a period of $1 \mathrm{~min}$ for every $10 \mathrm{~min}$, resulting in six such analysed minutes per hour and $108 \mathrm{~min}$ within the daily 18-h observation period. The walking speed was calculated in relation to the distance covered $\left(\mathrm{m} \mathrm{h}^{-1}\right)$ and in relation to the body length $\left(\mathrm{BL} \mathrm{h}^{-1}\right)$.

The position of the lobster within the maze, i.e. the square where the lobster stayed, was determined every $2 \mathrm{~min}$. Prior to the experiments, the average walking speed of the lobsters was evaluated. It amounted to $2 \mathrm{~m} \mathrm{~min}^{-1}$. Within $2 \mathrm{~min}$ the lobster could cross the entire basin and return to the starting point. Accordingly, the lobster could move to any square of the maze. Therefore, the collected data were treated like independent data.

The distances and the durations of every excursion from the shelter were measured. The results were grouped into 10 classes. The first class reached up to $0.5 \mathrm{~m}$ of walking distance. It covered the area around the shelter, which was on a straight line to the entrance. The limits of each of the subsequent classes of distances increased progressively by a factor of two. Finally, the number of shelter visits was counted and the time spent in shelters was measured.

\section{Statistics}

Walking speed data were averaged every hour. Data sets were statistically analysed with the computer program SigmaStat (SPSS Inc.). Due to the lack of normal distribution, one way Kruskal-Wallis ANOVA on ranks and a multiple comparison procedure (Student-Newman-Keuls test for ANOVA on ranks) were used.

The relationship between body length and relative locomotory activity was analysed by linear regression.

The randomness of distribution of each lobster was analysed with a $\chi^{2}$-test.

$$
\chi^{2}=\sum_{i} \sum_{j} \frac{(O \ddot{i j}-E i j)^{2}}{E i j} \quad(O=\text { observed frequency, } E=\text { expected frequency })
$$

In each experiment the lobster had the choice to occupy one of the 127 squares (126 degrees of freedom, $\left.\chi_{0.05,126}^{2}=153.8\right)$.

\section{Results}

\section{Locomotory performance}

During the $3 \mathrm{~h}$ of light before the onset of darkness (15:00 to 18:00) the lobsters remained in their shelters without any remarkable activity. However, within $5 \mathrm{~min}$ after the onset of darkness all lobsters left their shelters and moved through the maze. The average 


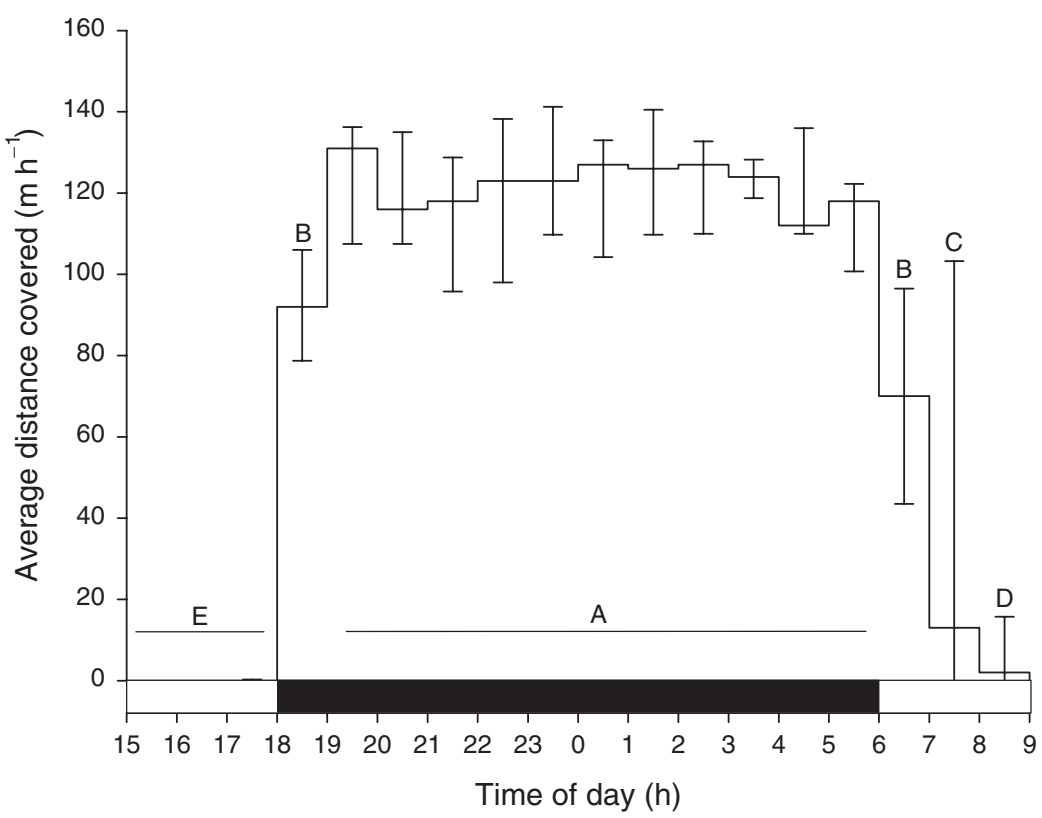

Figure 2. Average distance covered per hour (median, 25th and 75th percentiles, $n=9$ ). The dark phase between 18:00 and 06:00 is illustrated by the black bar above the time axis. Data, which do not share the same letter are significantly different from each other (Kruskal-Wallis ANOVA on ranks) and pairwise multiple comparison procedure (Student-Newmann-Keuls test for ANOVA on ranks, $p<0.05)$.

locomotory activity increased significantly during the first hour of darkness towards $92 \mathrm{~m} \mathrm{~h}^{-1}$ (Figure 2). During the dark period (18:00 to 06:00) average activity ranged between 92 and $127 \mathrm{~m} \mathrm{~h}^{-1}$. The maximum activity recorded for an individual lobster was $165 \mathrm{~m} \mathrm{~h}^{-1}$. The statistical analysis showed significant differences between the data sets ( $p \leq 0.001$, ANOVA on ranks). However, no significant differences were evident within the hours of the dark phase between 20:00 and 06:00. The locomotory activities before dark (15:00-18:00) were significantly lower than the activities during all other hours. After the dark phase, the activities of the lobsters decreased continuously. Larger animals retreated to the shelter earlier than smaller animals. A few lobsters remained active even in the third hour after darkness. These distinct differences between individuals are reflected by the pronounced standard deviations in the post-dark period (06:00 to 09:00). Finally, all lobsters returned to their shelters, usually to that one which they had occupied before the dark phase. The total average distance covered by the lobsters during the entire night amounted to $1400 \mathrm{~m}$.

The relative locomotory activity expressed as body length per min ranged between 15.2 and $27.4 \mathrm{BL} \mathrm{min}^{-1}$. The relative activity was inversely correlated to the total length of the animals (Figure 3). The smallest lobsters (70 to $80 \mathrm{~mm}$ ) covered distances of about $25 \mathrm{BL} \mathrm{min}^{-1}$, while the largest lobster $(115 \mathrm{~mm})$ covered on average $15 \mathrm{BL} \mathrm{min}^{-1}$.

\section{Spatial distribution within the maze}

All lobsters utilized the entire maze but each lobster showed an individual pattern of distribution within the maze. An example for two selected animals (1237/99 and 987/99) is given in Figure 4. During the dark period the lobster no. 1237/99 stayed in and around each 


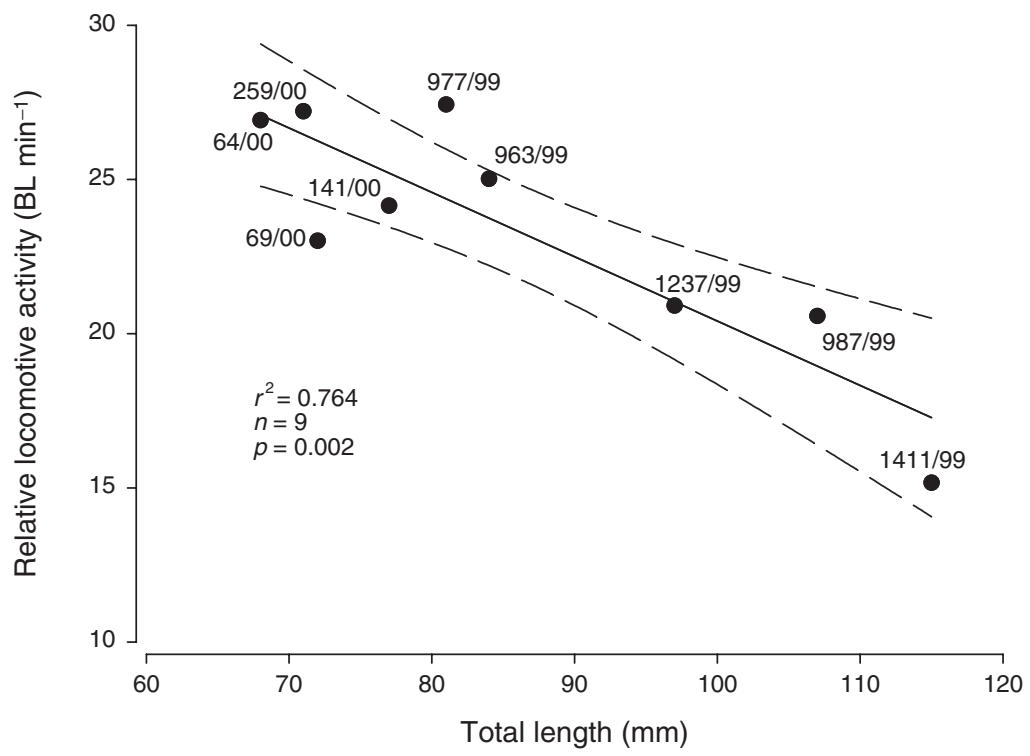

Figure 3. Correlation between total body length $(\mathrm{mm})$ and relative locomotory activity $\left(\mathrm{BL} \mathrm{min}{ }^{-1}\right)$ during the dark phase. Individuals are designated by their IDs. The regression parameters, the regression line (solid) and the $95 \%$ confidence interval (dashed) are shown.
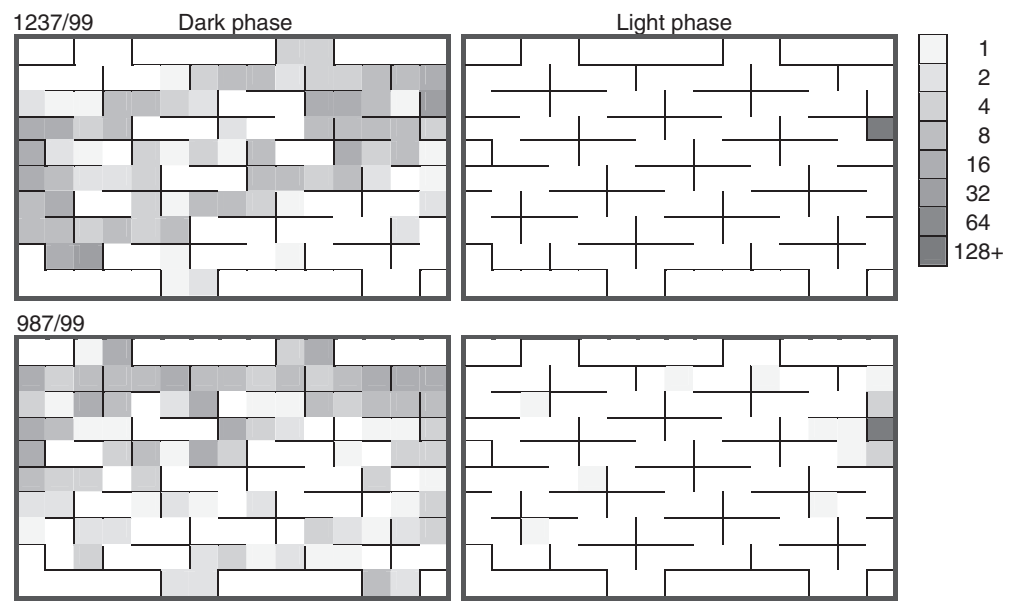

Figure 4. Spatial distribution in the maze of lobster no. 1237/99 and lobster no. 987/99 during the dark phase and the light phase. During the experiment the position of the lobsters were recorded every $2 \mathrm{~min}$. The frequencies of appearance on single partitions of the maze were classified as indicated in the legend and plotted on the outline of the maze. White squares indicate no observation. Inaccessible areas of the basin also remained white.

of the two shelters A5 and O4. Furthermore, one area of elevated frequency of abundance appeared across the maze from $\mathrm{B} 7 / \mathrm{B} 8$ to the opposite side of the basin $(\mathrm{O} 2)$, as well as from the shelter A5 towards the squares $\mathrm{H} 2$ and $\mathrm{I} 2$ further towards the surrounding of the opposite shelter (O2). During the light period lobster no. 1237/99 remained constantly in shelter $\mathrm{O} 2$. 
Table II. Shelter preference and results of $\chi^{2}$-analysis on the randomness of distribution of individual lobster during the dark phase (D) and the light phase (L), degrees of freedom: $126, \chi^{2}{ }_{0.05,126}=153.8$.

\begin{tabular}{lccr}
\hline Individual & Preferred shelter & $\chi^{2}(\mathrm{D})$ & $\chi^{2}(\mathrm{~L})$ \\
\hline $64 / 00$ & Left & 962.9 & 13320 \\
$259 / 00$ & Left & 234.8 & 16626 \\
$69 / 00$ & Left & 526.9 & 9747 \\
$141 / 00$ & Right & 902.9 & 18826 \\
$977 / 99$ & Both & 309.6 & 8813 \\
$963 / 99$ & Left & 206.1 & 12914 \\
$1237 / 99$ & Right & 564.3 & 20738 \\
$987 / 99$ & Right & 507.1 & 18816 \\
$1411 / 99$ & Right & 312.2 & 18150 \\
\hline
\end{tabular}

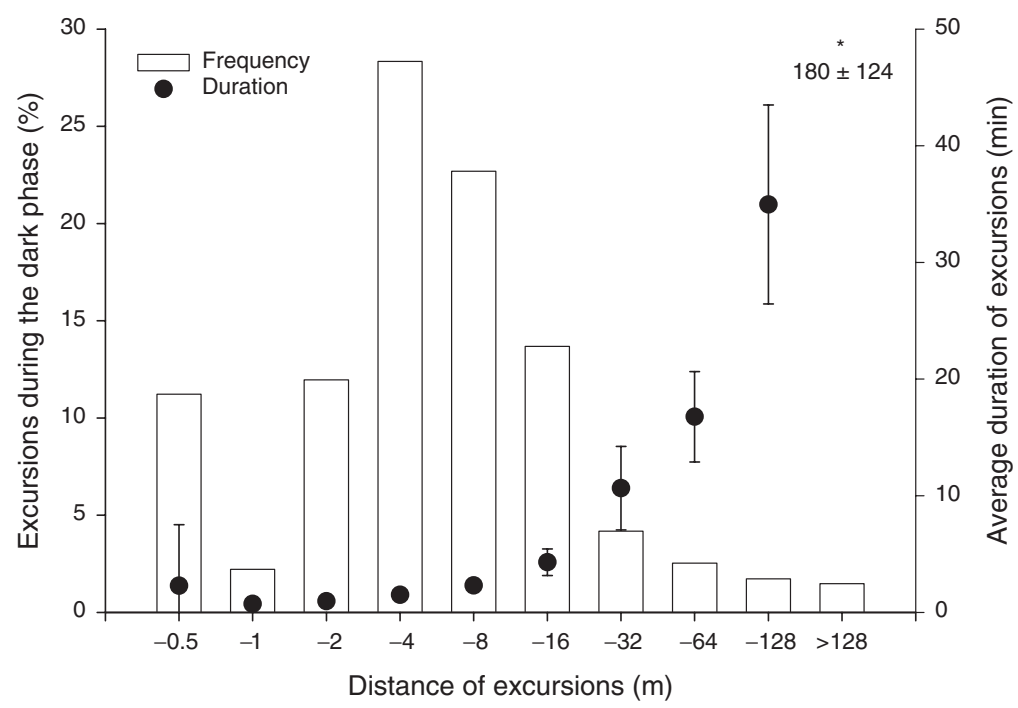

Figure 5. Relative frequencies (left axis) and average durations (right axis) of excursions during the dark phase in relation to the distances of excursions. The average duration of excursions of more than $128 \mathrm{~m}$ was $180 \pm 124 \mathrm{~min}$ (data not included in graph).

The other lobster, no. 987/99, also alternated between the shelters but predominantly stayed close to the edge of the basin, most frequently in the squares in columns $\mathrm{A}, \mathrm{B}$ and C. During the light period this lobster also preferred to stay in the shelter at O2. However, in contrast to lobster no. $1237 / 99$ it left the shelter for a few short excursions.

The $\chi^{2}$-analysis showed that the distribution of every lobster varied significantly from the expected average distribution within the maze (Table II).

\section{Excursions}

About $11 \%$ of all excursions in the maze covered only up to $0.5 \mathrm{~m}$ (Figure 5). This corresponds to the maximum distance away from the shelter of $0.2-0.3 \mathrm{~m}$. It allowed the lobsters to return straight back to the shelter. These excursions lasted $2.3 \mathrm{~min}$ on average (Figure 5). Only $2 \%$ of all excursions were between 0.5 and $1 \mathrm{~m}$. 


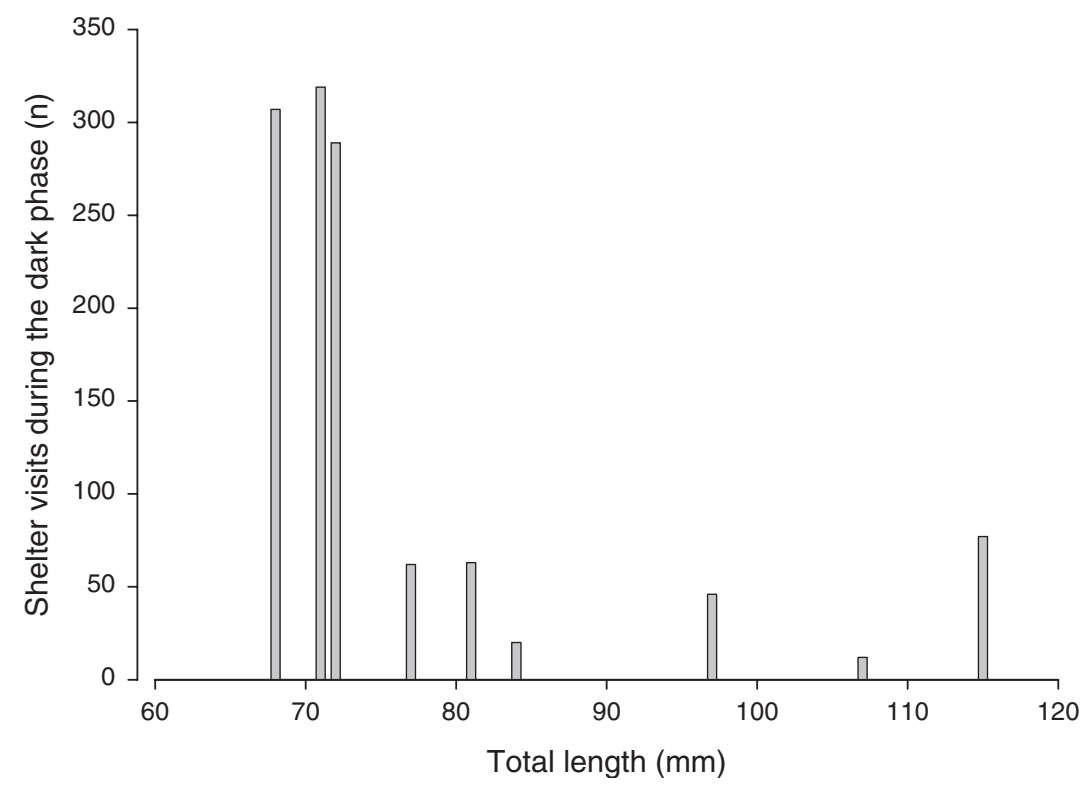

Figure 6. Frequency of shelter visits of juvenile lobsters in relation to their body length.

Excursions between 1 and $2 \mathrm{~m}$ became more frequent again (12\%). These lasted on average less than $1 \mathrm{~min}$. Most excursions (28\%) ranged between 2 and $4 \mathrm{~m}(1.5 \mathrm{~min}), 4$ and $8 \mathrm{~m}$ $(23 \%, 2.3 \mathrm{~min})$ and 8 and $16 \mathrm{~m}(14 \%, 4.3 \mathrm{~min})$. The frequency of further excursions beyond $16 \mathrm{~m}$ decreased gradually from 4 to $1 \%$ and the duration increased exponentially up to $180 \mathrm{~min}$ on average. Overall, $90 \%$ of all excursions within the maze covered less than $16 \mathrm{~m}$. The average time for these excursions did not exceed $5 \mathrm{~min}$.

\section{Shelter visits}

Small lobsters visited their shelters more often than larger lobsters (Figure 6). Small individuals visited the shelters about 300 times per night. Larger lobsters showed on average only 50 shelter visits per night. Both shelters were visited, but generally one shelter was preferred as a "home" shelter. The relation between home shelter visits and foreign shelter visits was not obviously linked to the size of the lobsters and ranged between 60 and $90 \%$ of all visits.

Small lobsters also spent more time within the shelters than larger ones (Figure 7). The residence time decreased exponentially with lobster size and ranged between $10 \%$ and about $1 \%$ of the dark period.

\section{Discussion}

We are well aware of the restrictions of a laboratory study in contrast to a field study. Certainly, the numerical data gained cannot be transferred to a situation in the wild. This is particularly so in view of the exceptionally complex repertoire of behaviour in lobsters. Nevertheless, we hope that some principles of lobster behaviour were described, which may be helpful in designing future field experiments and in rearing lobster in culturing endeavours. 


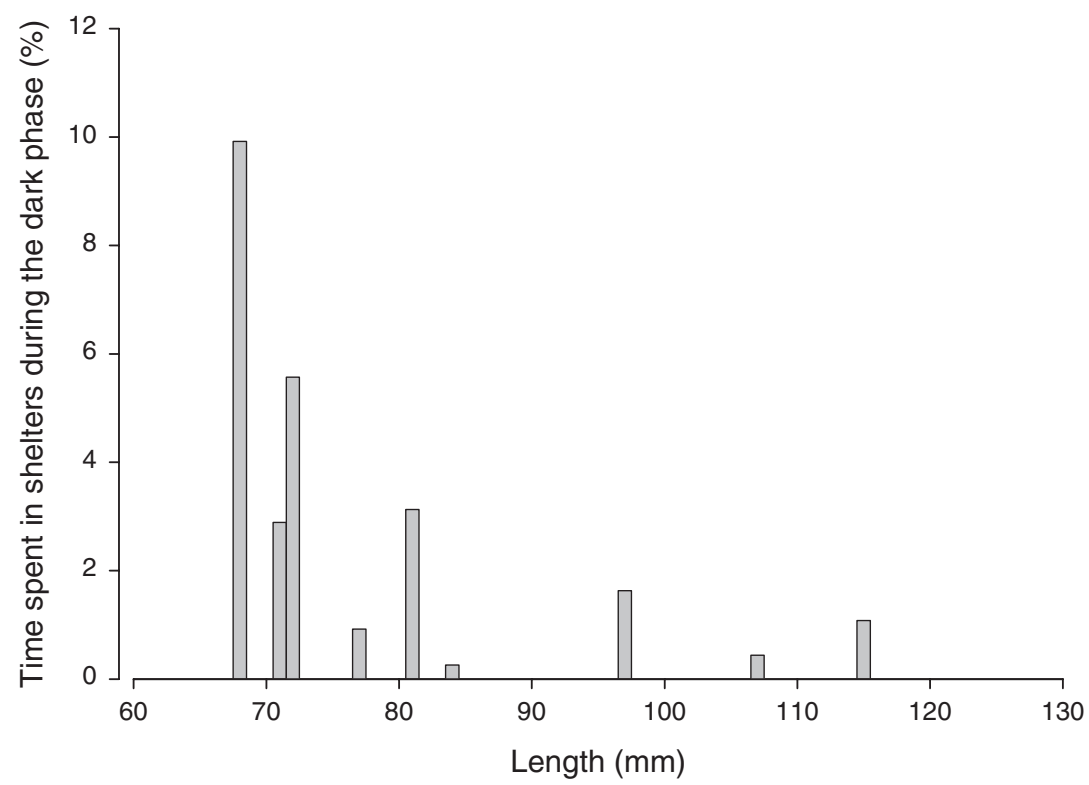

Figure 7. Time spent in shelters in relation to body length of juvenile lobsters.

Newly settled post-larvae or early benthic phase (EBP) lobsters are most vulnerable to various predators such as fish and other crustaceans. Behavioural studies on stage IV American lobsters (Homarus americanus) have shown that these early juveniles remain within their burrows during day and night. They feed on prey from the substrate around their burrow entrances and swirl plankton into the burrow by pleopod fanning (Barshaw \& Bryant-Rich 1988). As the early stages grow, the juveniles increase their nocturnal activity. Cooper and Uzmann (1980) reported that juvenile American lobsters became nocturnally active at a size of approximately $45 \mathrm{~mm}$ carapace length. We found that all of the juvenile European lobsters ranging from 27 to $41 \mathrm{~mm}$ of carapace length already exhibited distinct nocturnal exploration behaviour. Within $5 \mathrm{~min}$ after the lights were switched off, they left their shelters and started to roam through the entire maze. The overall routes covered by the lobsters during the 12-h dark phase were surprisingly high, ranging between 1200 and $1600 \mathrm{~m}$. Although there was no significant relation between lobster size and total route covered, a significant negative correlation existed between lobster size and the relative locomotory performance expressed as body length per minute. Accordingly, the relative activity of smaller individuals was higher than that of larger ones.

The juvenile lobsters in our study remained equally active during the entire night. This is in contrast to adult European lobsters, which showed a peak of locomotory activity within the first half of the night (Smith et al. 1998). The authors suggested that this activity peak was partly due to increased foraging activity after fasting during the daytime. Similarly, Wickins et al. (1996) found that juvenile lobsters spent more time outside their burrows the longer they were starving. However, within the first two days of the 10-day experiment no significant increase was evident. Our animals were fed before the acclimation period but remained unfed during the experiment. The starvation period did not exceed two days. Accordingly, increased locomotory activity as a result of starvation seems unlikely in our experiments. 
During the light period the lobsters remained in their shelters and left them only occasionally. These results are in good agreement with Ulrich (1998) who found that two-year-old European lobsters spent $82 \%$ of the daytime, but only $5 \%$ of the night time, within their shelters. An endogenous activity rhythm can be neglected because Ulrich (1998) reported that during a 54-h permanent illumination period the lobsters remained within their shelters for $95 \%$ of the time. In contrast, the lobsters spent only about $1 \%$ of the time within shelters during a subsequent $89 \mathrm{~h}$ dark period.

The use of 'home' shelters has been described for both, the American lobster, and the European lobster (Ennis 1984; Karnofsky et al. 1989; Smith et al. 1998). Shelter size is crucial to the behaviour of lobsters (Cobb 1971) in the field as well as in the laboratory. According to Cobb (1971) lobsters prefer shelter profiles with a height-width ratio of $1: 2$. Small lobsters of 36 to $46 \mathrm{~mm}$ carapace length preferred shelters of $5 \times 10 \mathrm{~cm}$ and $7.5 \times 15 \mathrm{~cm}$, respectively (Richards \& Cobb 1986). Accordingly, the shelter size of $3 \times 6 \mathrm{~cm}$ in our experiments may be considered adequate for our lobsters, which had a carapace length of 27 to $41 \mathrm{~mm}$. Indeed, every lobster did establish a 'home' shelter to which it regularly returned and, sooner or later, remained in when the light phase began.

The frequency as well as the duration of shelter visits decreased exponentially with the size of the lobsters. An apparent base level of about 20 to 50 shelter visits per night and $1-2 \%$ shelter duration was observed in larger lobsters. This indicates that smaller lobsters are more dependent on the presence and the rapid attainability of their shelters than larger ones. In field studies small lobsters preferred to stay in shelters and in the clefts between stones and cobble. This is probably the reason why juvenile European lobsters were rarely captured nor observed in the wild (Linnane et al. 2001; Mercer et al., 2001; van der Meeren, 2001). The larger lobsters, in contrast, exhibited more active exploration behaviour. These results are in agreement with Cobb and Wahle (1994) who reported that juvenile lobsters increase their movement range within the first few years of benthic life as a consequence of a developmental change in behaviour. Hypothetically, they must progressively emerge as they grow in order to cover their increasing nutritional demand that they cannot meet within or around the shelter. As the demand for food continuously increases with size, it can be expected, that the duration of emergence also increases continuously. However, our results indicate, that a shift in shelter utilization appears rapidly within a comparatively narrow size range around $75 \mathrm{~mm}$. It seems, as if the juvenile lobsters switch from a defensive mode of behaviour into a more offensive and active mode. This behavioural shift drastically improves their ability to cope with predators and competitors. However, the physiological or morphological reasons for this behavioural change remain to be investigated.

The distances of excursions that the lobsters covered in the maze between subsequent shelter visits varied slightly between individuals. However, all the observed lobsters showed a distinct non-random graduation of their explorative activity, which can be grouped into three categories. About $10 \%$ of all excursions were carried out within the immediate surrounding of the shelter allowing for a straight and rapid return to the shelter. Longer excursions that covered up to $1 \mathrm{~m}$ in the maze were less frequent, amounting to only about $5 \%$ of all excursions. These observations are in accordance with Lawton (1987) who showed that juvenile $H$. americanus of the same size range as our European lobsters (with a carapace length of $20-46 \mathrm{~mm}$ ) spent most of their time on activities within or close to the shelter, i.e. within a range of 20 to $30 \mathrm{~cm}$ from the shelter. Our results show that longer excursions that covered between 2 and $8 \mathrm{~m}$ in the maze became more frequent $(63 \%)$ again. However, only $10 \%$ of all excursions exceeded $16 \mathrm{~m}$. It seems that the juvenile lobsters distinguished between short "front-yard trips" and intermediate "field walks". 
Some lobsters even performed "extended marches" of more than $250 \mathrm{~m}$. The reason for the "front-yard trips" may be to establish an individual environment around the shelter entrance (Karnofsky et al. 1989) and to evaluate the presence of predators and competitors. van der Meeren (2001) observed that small lobsters of carapace length below $45 \mathrm{~mm}$ defended their shelters against competitors. Furthermore, smaller lobsters are more vulnerable to predation risk. Accordingly, in order to avoid predation, these lobsters spent more time within their shelters and visited the shelters more frequently than larger ones. Apparently, since no predators were present in our experiments, the lobsters were not limited in their activity and explored the entire maze performing "field walks" in search for food and better shelters. The "extended marches" of larger lobsters - if transferred into the natural environment - may be considered small-scale migrations in order to change habitats. The largest lobster in our experiment even left the shelters for almost $5 \mathrm{~h}$ covering a route of $750 \mathrm{~m}$ in the maze.

None of the observed lobsters showed a random distribution within the maze but exhibited an individual distribution pattern. The frequency of appearance was elevated near the shelter since the lobsters spent a significant share of their time in and around the shelters. Moreover, each of the lobsters developed a preference for certain areas within the maze. These results may indicate that juvenile lobsters already start to establish preferred areas or territories. The extension of a potential territory in the natural environment may be estimated from the distances of excursions from the home shelter. More than $75 \%$ of all excursions were shorter than $8 \mathrm{~m}$ and $90 \%$ of all excursions were within a distance of $16 \mathrm{~m}$. Accordingly, the maximum distance away from the shelter would amount to 4 and $8 \mathrm{~m}$, respectively. Assuming a prevalently straight walking direction and an excursion distance of 4 to $8 \mathrm{~m}$ radially away from the shelter and back to it, juvenile lobsters would be able to occupy a maximum circular territory of 12 to $50 \mathrm{~m}^{2}$. However, the actual shape and characteristic of a territory in the wild is defined by the topography of the area, the distribution of barriers such as rocks or boulders and also the individual preferences of lobsters (Jensen et al. 1993; Karnofsky et al. 1989). Accordingly, $12-50 \mathrm{~m}^{2}$ may be considered the theoretical upper limit of a potential territory rather than the actual space that a juvenile lobster would cover.

In conclusion, this behavioural study showed that juvenile lobsters possess an extensive nocturnal locomotory activity and exploration behaviour in the laboratory. The frequency of shelter visits decreased rapidly with lobster size. A stable level was reached in lobsters larger than $75 \mathrm{~mm}$. Apparently, the larger lobsters were less dependent on the attainability of shelters and thus can more intensively explore and utilize their environment. These findings should be taken into account in the planning and realization of restocking programmes. In order to improve survival, reared lobsters should be grown to a size of $75-80 \mathrm{~mm}$. Assuming favourable growth conditions in the rearing facility at the AWI marine station, lobsters could reach this size at the end of the second year (Mehrtens, personal communication). Furthermore, we will try to verify this size-threshold of activity by observation of tagged lobsters in the field.

\section{Acknowledgements}

We thank Mr Gerrit Sahling and Ms Laura Roecken for technical support and Dr Lars Gutow and Dr Luis Gimenez for critical comments on the manuscript. The lobster-rearing program was financially supported by the Ministry of Fisheries and Agriculture of the State of Schleswig Holstein by a grant to FB. 


\section{References}

Barshaw DE, Bryant-Rich DR. 1988. A long-term study on the behavior and survival of early juvenile American lobster, Homarus americanus, in three naturalistic substrates: eelgrass, mud, and rocks. Fish. Bull. 86:789-796.

Cobb JS. 1971. Shelter-related behavior of the Lobster, Homarus americanus. Ecology 52:108-115.

Cobb JS, Wahle RA. 1994. Early life history and recruitment processes of clawed lobsters. Crustaceana 67:1-25.

Cooper RA, Uzmann JR. 1980. Ecology of juvenile and adult Homarus. In: Cobb JS, Phillips BF, editors. The biology and management of lobsters. Volume II: Ecology and management. New York: Academic Press. pp. 97-142.

Ehrenbaum E. 1894. Der Helgoländer Hummer, ein Gegenstand der deutschen Fischerei. Wiss. Meeresunters. NF 1:278-300.

Ennis GP. 1984. Territorial behavior of the American lobster Homarus americanus. Trans. Am. Fish. Soc. $113: 330-335$.

Goemann O. 1990. "Echt” Helgoländer Hummer. Oldenburg: Kohlrenken Verlag. p. 88.

Harms J, Schilling U, Goemann O. 1995. Der Helgoländer Hummer. Natur und Museum 125:33-68.

Holthuis LB. 1974. The lobsters of the superfamily Nephropidea of the Atlantic Ocean (Crustacea: Decapoda). Bull. Mar. Sci. 24:723-884.

Jensen AC, Collins KJ, Free EK, Bannister CA. 1993. Lobster (Homarus gammarus) movement on an artificial reef: The potential use of artificial reefs for stock enhancement. Crustaceana 67:198-211.

Karnofsky EB, Atema J, Elgin RH. 1989. Field observations of social behavior, shelter use, and foraging in the lobster Homarus americanus. Biol. Bull. 176:239-246.

Lawton P. 1987. Diel activity and foraging behavior of juvenile American lobsters, Homarus americanus. Can. J. Fish. Aquat. Sci. 44:1195-1205.

Linnane A, Brendan B, Mercer JP, Browne R, van der Meeren G, Ringvold H, Bannister C, Mazzoni D, Munday B. 2001. Searching for the early benthic phase (EBP) of the European lobster: a trans-European study of cobble fauna. Hydrobiologia 465:63-72.

Lozán JL, Lenz W, Rachor E, Watermann B, von Westernhagen H. 1990. Warnsignale aus der Nordsee: Wissenschaftliche Fakten. Berlin: Verlag Paul Parey. 431pp.

Mercer JP, Bannister RCA, van der Meeren GI, Debuse V, Mazzoni D, Lovewell S, Brown R, Linnane A, Ball B. 2001. An overview of the LEAR (Lobster Ecology And Recruitment) project: results of field and experimental studies on the juvenile ecology of Homarus gammarus in cobble. Mar. Freshw. Res. 52:1291-1301.

Richards RA, Cobb JS. 1986. Competition for shelter between lobsters (Homarus americanus) and Jonah crabs (Cancer borealis): effect of relative size. Can. J. Fish. Aquat. Sci. 43:2250-2255.

Smith IP, Collins KJ, Jensen AC. 1998. Movement and activity patterns of the European lobster, Homarus gammarus, revealed by electromagnetic telemetry. Mar. Biol. 132:611-623.

Ulrich I. 1998. Populationsgenetische und verhaltensbiologische Untersuchungen am Helgoländer Hummer, Homarus gammarus (L.). Dissertation, Universität Hamburg, 176pp.

Ulrich I, Müller J, Schütt C, Buchholz F. 2001. A study of population genetics in the European lobster Homarus gammarus (Decapoda, Nephropidae). Crustaceana 74:825-837.

van der Meeren GI, Næss H. 1991. Recatches of marked lobsters, Homarus gammarus, released in 1988. ICES CM, K 7:1-9.

van der Meeren GI. 2001. Effects of experience with shelter in hatchery-reared juvenile European lobster (Homarus gammarus). Mar. Freshw. Res. 52:1487-1493.

Wickins JF, Roberts JC, Heasman MS. 1996. Within-burrow behaviour of juvenile European lobsters Homarus gammarus (L.). Mar. Freshw. Behav. Physiol. 28:229-253.

Williams AB. 1988. Lobsters of the world - an illustrated guide. New York: Huntington, Osprey Books. 186pp. 